\title{
PENGUKURAN KINERJA SUPPLY CHAIN CV. X BERDASARKAN LIMA PROSES INTI MODEL SUPPLY CHAIN OPERATIONS REFERENCE (SCOR)
}

\author{
Dadang Surjasa $^{1}$, Ahmad $^{2}$ dan Elvi Irawati ${ }^{2}$ \\ ${ }^{1}$ Program Studi Teknik Industri Jurusan Teknik Industri Universitas Trisakti \\ ${ }^{2}$ Program Studi Teknik Industri Jurusan Teknik Mesin Universitas Tarumanagara \\ e-mail: elvi_blue@ymail.com¹,d_surjasa@yahoo.com², ahmadmambas@yahoo.com
}

\begin{abstract}
ABSTRAK
CV. X merupakan perusahaan manufaktur yang bergerak dalam industri furniture. Dalam aktivitas bisnisnya, aliran supply chain memiliki peran yang sangat penting, mulai dari pasokan bahan baku dari supplier sampai produk jadi ke konsumen. Oleh karena itu dilakukan suatu analisis untuk mengukur dan menilai sejauh mana kinerja supply chain perusahaan telah tercapai. Tujuan dari penelitian ini adalah untuk mengetahui hasil kinerja supply chain sehingga dapat memberikan usulan perbaikan bagi indikator kinerja perusahaan yang masih jauh di bawah target. Pengukuran kinerja supply chain ini didasarkan pada lima proses inti pada metode SCOR. Kemudian dilakukan pembobotan menggunakan pairwise comparison untuk masing-masing proses inti, atribut kinerja dan KPI-nya serta scoring system dengan menggunakan OMAX dan analisis dengan Traffic Light System. Hasil penelitian menunjukkan bahwa kinerja supply chain perusahaan paling rendah berada pada bulan Agustus 2016 dengan nilai 3.698. Dari 17 KPI yang valid, terdapat 2 KPI kategori hijau, 7 KPI kategori kuning dan 8 KPI dengan kategori merah. Berdasarkan hasil tersebut, maka diberikan usulan perbaikan untuk 8 KPI dengan kategori merah yang diharapkan dapat meningkatkan kinerja supply chain perusahaan. Sebagai contoh usulan untuk KPI RRL 1.3 (jumlah keluhan mengenai produk dari konsumen), yaitu membuat lembar keluhan yang berisikan tanggal, nama konsumen serta jenis keluhan dari konsumen.
\end{abstract}

Kata Kunci: SCM, SCOR, Pairwise Comparison, OMAX, Traffic Light System

\begin{abstract}
$C V . X$ is a manufacturing company engaged in the furniture industry. In its business activities, the supply chain flows have a very important role, ranging from the supply of raw materials to finished products from the supplier to the consumer. Therefore do an analysis to measure and assess the extent to which the company's supply chain performance has been achieved. The purpose of this study was to determine the result of the performance of the supply chain so as to provide proposals for the improvement of company performance indicators which are still far below the target. Supply chain performance measurement is based on five core processes on the method of SCOR. Then weighted using pairwise comparison for each core process, performance attributes and KPIs, and then scoring system using OMAX and analysis with Traffic Light System. The results showed that the lowest company's supply chain performance is in August 2016 with a value of 3,698. Of the 17 KPI valid, there are 2 KPI with green categories, 7 KPI with yellow categories and 8 KPI with read categories. Based on these results, it is provided the proposed improvements to 8 KPI with red categories to improve the performance of supply chain companies. For example, proposals for KPI RRL 1.3 (the number of consumer complaints about products), which is making the complaint sheet containing the date, name and type of consumer complaints from consumers.
\end{abstract}

Keywords: SCM, SCOR, Pairwise Comparison, OMAX, Traffic Light System

\section{PENDAHULUAN}

Supply chain merupakan hal yang sangat penting untuk diperhatikan, di mana aktivitas supply chain merupakan suatu proses yang sangat berpengaruh terhadap performansi perusahaan karena bukan hanya berhubungan dengan masalah internal namun juga eksternal dari perusahaan tersebut. Saat ini persaingan yang terjadi bukan lagi antara perusahaan dengan perusahaan lainnya, tetapi antara supply chain yang satu dengan supply chain yang lainnya [1].

CV. X merupakan salah satu perusahaan furniture dengan produk sofa. Dalam menghasilkan produknya, CV. X bekerja sama dengan berbagai pihak mulai dari pihak supplier sebagai pemasok bahan baku, pihak jasa pengiriman (ekspedisi) dan juga para karyawan yang bekerja di dalam perusahaan. Dengan banyaknya pihak yang terlibat dalam aliran supply chain ini, CV. X sering 
mengalami beberapa permasalahan. Beberapa permasalahan tersebut, seperti adanya keluhan dari pelanggan mengenai keterlambatan pengiriman sofa yang dapat mencapai 2 minggu hingga 1 bulan serta adanya keluhan mengenai kecacatan produk jadi. Kecacatan produk jadi dapat berupa patahnya kaki sofa, adanya kerusakan pada lengan sofa serta kulit sofa yang rusak atau lecet.

Hal ini dapat disebabkan karena pihakpihak dalam aliran supply chain perusahaan belum mengetahui sejauh mana tingkat kinerja supply chain yang telah mereka capai. Oleh karena itu, perlu dilakukan suatu pengukuran kinerja supply chain agar pihak-pihak yang terlibat dapat mengetahui apakah kinerja supply chain dalam perusahaan sudah berjalan efektif dan efisien atau belum.

Pengukuran kinerja ini didasarkan pada lima proses inti pada model Supply Chain Operation Reference (SCOR). Model SCOR merupakan suatu cara yang dapat digunakan perusahaan untuk mengomunikasikan sebuah kerangka yang menjelaskan mengenai rantai pasok secara detail, mendefinisikan dan mengategorikan proses-proses yang dapat membangun indikator pengukuran kinerja yang diperlukan dalam pengukuran kinerja rantai pasok [2]. Dari hasil penelitian ini akan diberikan usulan perbaikan yang dapat meningkatkan kinerja supply chain CV. X.

Model SCOR adalah suatu model acuan dari operasi supply chain. SCOR pada dasarnya juga merupakan model yang berdasarkan proses. Model SCOR membagi proses-proses supply chain menjadi 5 proses inti, yaitu [1]: (1) Plan, yaitu proses yang menyeimbangkan permintaan dan pasokan untuk menentukan tindakan terbaik dalam memenuhi kebutuhan pengadaan, produksi, dan pengiriman. (2) Source, yaitu proses pengadaan barang atau jasa untuk memenuhi permintaan. (3) Make, yaitu proses untuk mentransformasikan bahan baku atau komponen menjadi produk yang diinginkan pelanggan. (4) Deliver, yaitu proses untuk memenuhi permintaan customer terhadap barang/jasa. (5) Return, yaitu proses pengembalian atau menerima pengembalian produk karena berbagai alasan.
Kelima proses inti tersebut juga diukur berdasarkan atribut kinerja SCOR yang terbagi menjadi customer facing (Reliability, Responsiveness, dan Agility) serta internal facing (cost dan asset), Atribut kinerja tersebut adalah sebagai berikut [3]: Reliability, yaitu kinerja supply chain dalam mengirimkan produk yang tepat dalam kondisi dan kemasan yang tepat pada waktu yang tepat, dan dengan kuantitas dan dokumen yang tepat kepada konsumen yang tepat. Responsiveness, yaitu kecepatan supply chain dalam menyediakan produk ke konsumen. Agility, yaitu kelincahan atau ketangkasan supply chain dalam merespon perubahan pasar dalam upaya mempertahankan keunggulan kompetitif. Cost, yaitu biaya yang terkait dengan operasi supply chain. Asset, yaitu efektivitas organisasi dalam mengelola asetnya untuk mendukung kepuasan pelanggan, termasuk seluruh pengelolaan aset tetap dan modal kerja.

Pairwise comparison merupakan matriks perbandingan berpasangan yang digunakan dalam studi ilmiah. Matriks perbandingan berpasangan sering digunakan dalam pengambilan keputusan multi-atribut, untuk menghitung bobot kriteria atau untuk mengevaluasi suatu alternatif terhadap suatu kriteria. Dalam matriks perbandingan berpasangan ini akan dibandingkan setiap pasangan kriteria maupun setiap pasangan alternative [4].

Dalam matriks perbandingan berpasangan, hal yang terpenting yang harus diperhatikan adalah masalah inconsistency. Untuk mengetahui konsistensi jawaban yang akan berpengaruh kepada kesahihan hasil, Prof. Saaty mendefinisikan ukuran konsistensi sebagai Consistency Index, yaitu [4]:

$\mathrm{CI}=\frac{\lambda \mathrm{maks}-\mathrm{n}}{\mathrm{n}-1}$

Untuk mengetahui apakah CI dengan besaran tertentu cukup baik atau tidak, perlu diketahui rasio yang dianggap baik, yaitu apabila $\mathrm{CR} \leq 0,1$. Rumus CR adalah [5]:

$\mathrm{CR}=\frac{\mathrm{CI}}{\mathrm{RI}}$ 
Objective matrix (OMAX) adalah suatu model pengukuran yang mengombinasikan pendekatan kuantitatif dan kualitatif. OMAX dapat digunakan untuk mengukur seluruh aspek kinerja yang dipertimbangkan dalam suatu unit kerja di mana indikator kinerja untuk setiap input dan output didefinisikan dengan jelas. Dalam perkembangannya, metode OMAX selain bisa digunakan untuk mengukur produktivitas juga digunakan untuk mengukur kinerja perusahaan yang tersusun atas berbagai kriteria pengukuran [5].

Traffic Light System digunakan untuk memberikan tanda pada scoring system untuk menunjukan apakah suatu KPI (key performance indicator) memerlukan suatu perbaikan atau tidak [5].

\section{METODE PENELITIAN}

Penelitian ini dimulai dengan melakukan studi lapangan dan studi pustaka agar dapat dilakukan identifikasi masalah. Setelah masalah teridentifikasi, selanjutnya dilakukan penetapan tujuan dan batasan masalah. Selanjutnya dilakukan pengumpulan dan pengolahan data dengan menggunakan metode yang sesuai dengan permasalahan yang dihadapi.

Pengumpulan data pada penelitian ini dilakukan dengan observasi lapangan, wawancara dengan pihak perusahaan mengenai aliran supply chain perusahaan, data-data perusahaan serta kuisioner untuk validasi KPI dan pembobotan KPI.

Setelah semua data yang dibutuhkan telah terkumpul, selanjutnya dilakukan pengolahan data dengan tahapan sebagai berikut:

Identifikasi aliran supply chain dilakukan dengan observasi lapangan dan wawancara dengan pihak perusahaan untuk kemudian dibuat kerangka aliran supply chain.

Identifikasi KPI dilakukan dengan wawancara dengan General Manager, Manajer PPIC dan Purchasing, Manajer Produksi, Manajer Pengiriman dan Manajer Marketing. Dari hasil wawancara ini akan didapatkan visi, misi dari perusahaan dan juga sasaran dari setiap bagian atau departemen sehingga dapat ditentukan indikator pengukuran kinerja setiap departemen (KPI) yang selanjutnya akan diklasifikasikan berdasarkan 5 proses inti
SCOR. Selanjutnya dilakukan validasi KPI untuk mengetahui apakah KPI tersebut telah benar-benar menggambarkan performansi supply chain perusahaan.

Setelah didapatkan KPI yang telah divalidasi, kemudian dibuat kuisioner matriks berpasangan untuk dilakukan pembobotan KPI. Perhitungan pembobotan KPI ini dilakukan dengan menggunakan matriks perbandingan berpasangan. Perhitungan skor pencapaian kinerja supply chain perusahaan dilakukan dengan menggunakan metode OMAX. Metode OMAX selain bisa digunakan untuk mengukur produktivitas juga digunakan untuk mengukur kinerja perusahaan yang tersusun atas berbagai kriteria pengukuran.

Analisis dengan traffic light system ini dilakukan untuk mengetahui apakah nilai skor dari masing-masing KPI perlu diperbaiki atau tidak.

Usulan perbaikan diberikan kepada KPI yang berkategori merah. Usulan perbaikan yang diberikan berupa tindakan yang dapat diimplementasikan pada perusahaan.

Metode penelitian ini ditampilkan dalam bentuk diagram alir yang dapat dilihat pada Gambar 1.

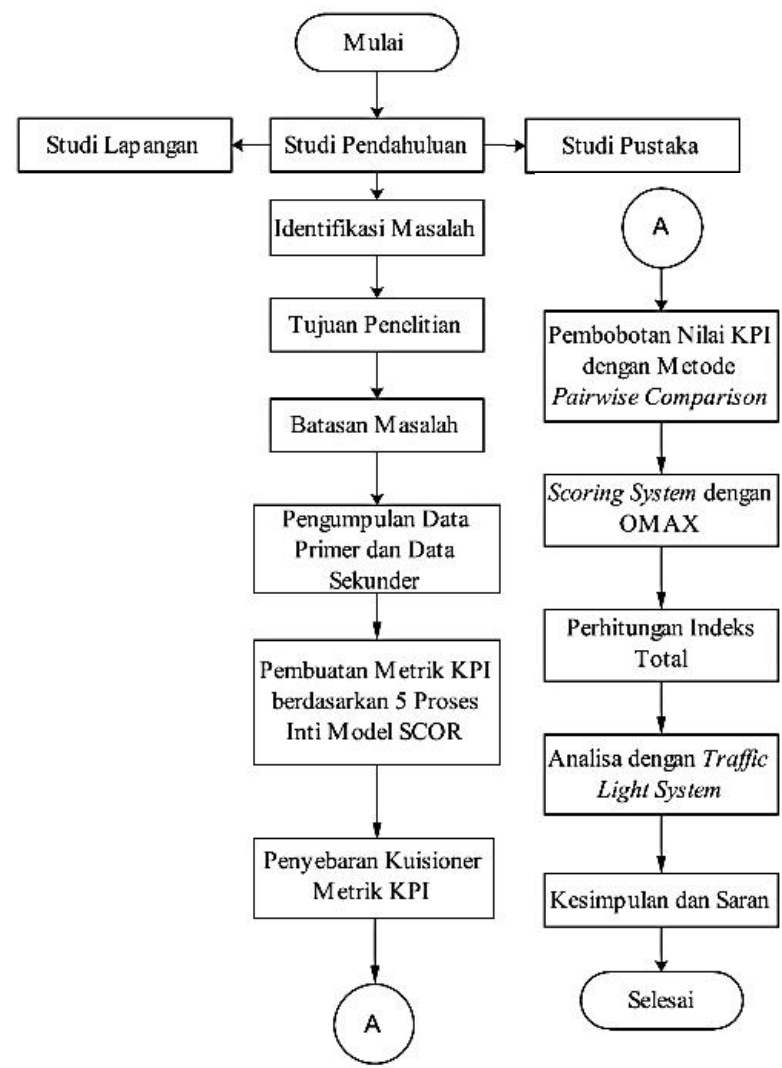

Gambar 1. Diagram Alir Metode Penelitian 


\section{HASIL DAN PEMBAHASAN}

Aliran supply chain CV. X terdiri dari aliran material, aliran uang, aliran informasi dan aliran barang return yang dapat dilihat pada Gambar 2. Dari Gambar 2 dapat diketahui bahwa aliran informasi terjadi saat adanya pesanan dari konsumen kepada bagian marketing dan kemudian bagian marketing akan melakukan konfirmasi dengan bagian pengadaan megenai persediaan bahan baku perusahaan. Selanjutnya bagian pengadaan akan melakukan pemesanan bahan baku yang dibutuhkan kepada supplier. Bukan hanya aliran informasi tetapi pada bagian pengadaan dan supplier juga terdapat aliran finansial (garis bewarna hijau) dan aliran barang return. Setelah itu, terdapat aliran material pada saat bahan baku dari supplier telah sampai di perusahaan. Bahan baku yang telah sampai kemudian diperiksa apakah sudah sesuai dengan spesifikasi serta jumlah yang dipesan. Bahan baku yang tidak sesuai akan di kembalikan kepada supplier dan bahan baku yang sudah sesuai spesifikasi akan dialirkan ke bagian produksi untuk diolah menjadi produk jadi. Sebelum memasuki tahap pengemasan, terlebih dahulu dilakukan pengecekan apakah sudah sesuai dengan pesanan konsumen dan juga dilakukan uji ketahaan sofa. Produk jadi yang tidak sesuai akan dialirkan kembali ke bagian produksi untuk di remake, sedangkan produk yang telah lulus pemeriksaan akan dikemas untuk kemudian dikirimkan kepada konsumen. Saat produk telah sampai ke konsumen, konsumen akan melakukan pengecekan sesuai keinginan mereka, jika produk tidak sesuai dengan pesanan mereka dan memiliki cacat, konsumen dapat memberikan informasi berupa keluhan kepada bagian marketing.

Setelah diketahui aliran supply chain perusahaan, selanjutnya dilakukan identifikasi metrik KPI yang didasarkan pada 5 proses inti (plan, source, make, deliver, dan return) model SCOR. Proses identifikasi ini dilakukan dengan brainstorming dan wawancara dengan pihak perusahaan. Dari hasil wawancara, studi literatur serta buku panduan SCOR versi 10.0 didapatkan 17 KPI yang valid dari total $25 \mathrm{KPI}$. 17 KPI ini terdiri dari 4 KPI dari proses plan, 3 KPI dari proses source, 4 KPI dari proses make, 3 KPI dari proses deliver dan 3 KPI dari proses return.

Untuk melakukan perhitungan bobot, terlebih dahulu dilakukan penyebaran kuisioner.

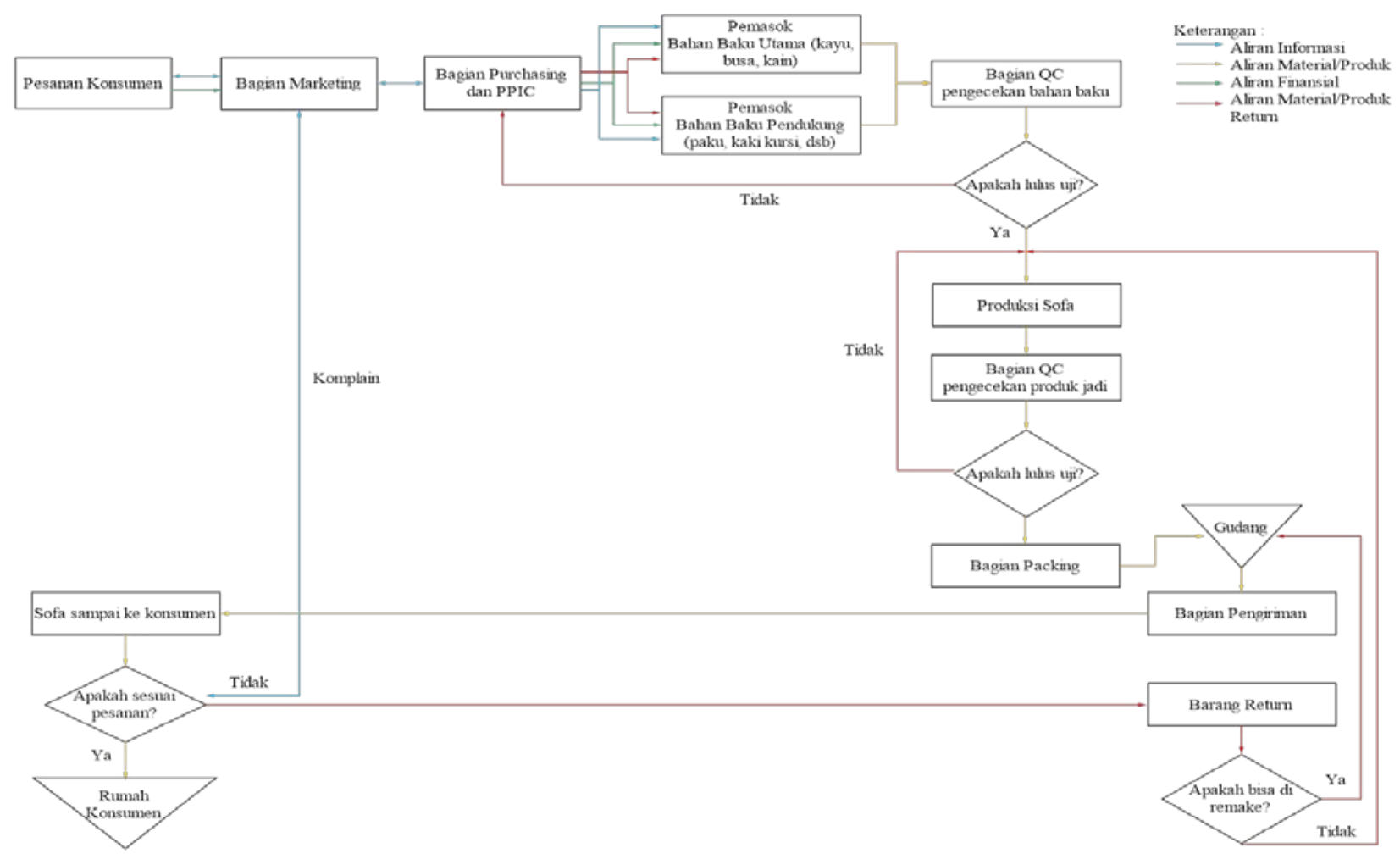

Gambar 2. Aliran Supply Chain CV. X 
Kuisioner matrik berpasangan yang berisi pernyataan KPI disebarkan kepada 5 pakar yang ahli dalam bidangnya, yaitu General Manajer, Manajer Produksi, Manajer PPIC, Manajer Marketing, dan bagian pengiriman. Setelah kuisioner diisi, kemudian dilakukan perhitungan pembobotan dengan menggunakan matriks perbandingan berpasangan yang dibantu dengan program Expert Choice 11. Hasil perhitungan bobot dapat dilihat pada Tabel 1.

Perhitungan scoring system dilakukan dengan menggunakan metode objective matrix (OMAX) dan traffic light system. Hasil scoring system untuk masing-masing proses inti pada bulan Agustus 2016 dapat dilihat pada Gambar 3 sampai Gambar 5.

Tabel 1. Hasil Perhitungan Bobot AHP

\begin{tabular}{|c|c|c|c|c|c|}
\hline Proses Inti & Bobot & Atribut Kinerja & Bobot & KPI (key performance indicator) & Bobot \\
\hline \multirow{4}{*}{ Plan } & \multirow{4}{*}{0,174} & \multirow{3}{*}{ Reliability } & \multirow{3}{*}{0,589} & $\begin{array}{l}\text { Kehandalan karyawan terkait dengan proses } \\
\text { perencanaan dilihat dari jumlah perencanaan } \\
\text { produksi yang terlambat }\end{array}$ & 0,516 \\
\hline & & & & $\begin{array}{l}\text { Hubungan antara bagian internal perusahaan } \\
\text { yang dapat mempengaruhi proses perencanaan } \\
\text { dilihat dari jumlah konflik yang sering terjadi }\end{array}$ & 0,18 \\
\hline & & & & $\begin{array}{l}\text { Persentase kesesuaian jumlah bahan baku kayu } \\
\text { yang tersedia dengan bahan baku kayu yang } \\
\text { dibutuhkan }\end{array}$ & 0,305 \\
\hline & & Responsiveness & 0,411 & $\begin{array}{l}\text { Rata-rata waktu yang dibutuhkan untuk } \\
\text { membuat perencanaan jadwal produksi }\end{array}$ & 1 \\
\hline \multirow{3}{*}{ Source } & \multirow{3}{*}{0,315} & \multirow{2}{*}{ Reliability } & \multirow{2}{*}{0,786} & $\begin{array}{l}\text { Presentase jumlah pengiriman bahan baku kayu } \\
\text { yang dapat dipenuhi oleh supplier }\end{array}$ & 0,786 \\
\hline & & & & $\begin{array}{l}\text { Presentase jumlah bahan baku kayu yang cacat } \\
\text { dari supplier }\end{array}$ & 0,214 \\
\hline & & Responsiveness & 0,214 & $\begin{array}{l}\text { Rata-rata lead time bahan baku kayu dari waktu } \\
\text { pesan hingga sampai }\end{array}$ & 1 \\
\hline \multirow{4}{*}{ Make } & \multirow{4}{*}{0,289} & \multirow{3}{*}{ Reliability } & \multirow{3}{*}{0,555} & $\begin{array}{l}\text { Kehandalan karyawan bagian produksi dilihat } \\
\text { dari kesesuaian jumlah produk yang dapat } \\
\text { dihasilkan dengan jumlah karyawan produksi }\end{array}$ & 0,639 \\
\hline & & & & $\begin{array}{l}\text { Persentase jumlah produk yang cacat selama } \\
\text { proses produksi }\end{array}$ & 0,2 \\
\hline & & & & $\begin{array}{l}\text { Persentase kesesuaian jumlah produk yang } \\
\text { dihasilkan dengan jumlah permintaan pesanan } \\
\text { yang ada }\end{array}$ & 0,161 \\
\hline & & Responsiveness & 0,445 & Rata-rata waktu pembuatan 1 produk & 1 \\
\hline \multirow{3}{*}{ Deliver } & \multirow{3}{*}{0,133} & \multirow{2}{*}{ Reliability } & \multirow{2}{*}{0,659} & $\begin{array}{l}\text { Persentase jumlah pengiriman pesanan yang } \\
\text { bisa dipenuhi dari total penerimaan pesanan }\end{array}$ & 0,509 \\
\hline & & & & $\begin{array}{l}\text { Persentase kesesuaian jumlah pesanan yang } \\
\text { dikirim dengan jumlah pesanan yang dipesan } \\
\text { oleh konsumen }\end{array}$ & 0,491 \\
\hline & & Responsiveness & 0,341 & $\begin{array}{l}\text { Kualitas hubungan dengan konsumen dilihat } \\
\text { dari kunjungan dari dan ke konsumen }\end{array}$ & 1 \\
\hline \multirow{3}{*}{ Return } & \multirow{3}{*}{0,089} & \multirow{2}{*}{ Reliability } & \multirow{2}{*}{0,445} & $\begin{array}{l}\text { Persentase produk cacat yang harus digantikan } \\
\text { kepada konsumen }\end{array}$ & 0,617 \\
\hline & & & & $\begin{array}{llll}\text { Jumlah keluhan mengenai produk dari } \\
\text { konsumen }\end{array}$ & 0,329 \\
\hline & & Responsiveness & 0,555 & $\begin{array}{l}\text { Rata- rata waktu yang dibutuhkan perusahaan } \\
\text { untuk mengganti produk cacat yang dikeluhkan } \\
\text { oleh konsumen (baik retail maupun end } \\
\text { customer) }\end{array}$ & 1 \\
\hline
\end{tabular}




\begin{tabular}{|c|c|c|c|c|c|c|c|c|c|c|}
\hline \multicolumn{2}{|l|}{ Plan } & \multicolumn{9}{|c|}{ Source } \\
\hline \multicolumn{2}{|c|}{ No. KPI } & $\begin{array}{l}\text { PRL } 1.2 \\
\end{array}$ & PRL 1.3 & PRL 2.1 & PRS3.1 & \multicolumn{2}{|c|}{ No. KPI } & SRL 2.1 & SRL 2.2 & SRS 2.1 \\
\hline \multicolumn{2}{|c|}{ Performance } & 15,837 & 2 & 104,094 & 4 & \multicolumn{2}{|c|}{ Performance } & 97,714 & 1,429 & 6 \\
\hline \multirow{11}{*}{ בัป } & 10 & 5 & 0 & 120 & 3 & \multirow{11}{*}{ בे } & 10 & 110 & 0 & 3 \\
\hline & 9 & 8,336 & 0,560 & 117,696 & 3,286 & & 9 & 108,480 & 0,177 & 3,369 \\
\hline & 8 & 11,671 & 1,119 & 115,392 & 3,571 & & 8 & 106,960 & 0,354 & 3,738 \\
\hline & 7 & 15,007 & 1,679 & 113,089 & 3,857 & & 7 & 105,440 & 0,531 & 4,107 \\
\hline & 6 & 18,342 & 2,238 & 110,785 & 4,143 & & 6 & 103,921 & 0,707 & 4,476 \\
\hline & 5 & 21,678 & 2,798 & 108,481 & 4,429 & & 5 & 102,401 & 0,884 & 4,845 \\
\hline & 4 & 25,014 & 3,357 & 106,177 & 4,714 & & 4 & 100,881 & 1,061 & 5,214 \\
\hline & 3 & 28,349 & 4 & 103,873 & 5 & & 3 & 99,361 & 1,238 & 5,583 \\
\hline & 2 & 30,213 & 4,944 & 102,920 & 5,667 & & 2 & 97,164 & 1,959 & 6,389 \\
\hline & 1 & 32,076 & 5,972 & 101,967 & 6,333 & & 1 & 94,966 & 1,951 & 7,194 \\
\hline & 0 & 33,940 & 7 & 101,014 & 7 & & 0 & 92,769 & 2,308 & 8 \\
\hline \multicolumn{2}{|c|}{ Score } & 6,751 & 6,426 & 3,096 & 6,50 & \multicolumn{2}{|c|}{ Score } & 2,251 & 2,465 & 2,483 \\
\hline \multicolumn{2}{|c|}{ Weight } & 0,516 & 0,18 & 0,305 & 1 & \multicolumn{2}{|c|}{ Weight } & 0,786 & 0,214 & 1 \\
\hline \multicolumn{2}{|c|}{ Value } & 3,484 & 1,157 & 0,944 & 6,500 & \multicolumn{2}{|c|}{ Value } & 1,769 & 0,528 & 2,483 \\
\hline
\end{tabular}

Gambar 3. Scoring System Proses Plan dan Source Bulan Agustus

\begin{tabular}{|c|c|c|c|c|c|}
\hline \multicolumn{2}{|c|}{ No. KPI } & MRL 2.1 & MRL 22 & MRL 23 & MRS 22 \\
\hline \multicolumn{2}{|c|}{ Performance } & 3,063 & 0,081 & 81,579 & 1,918 \\
\hline \multirow{11}{*}{ בัँ } & 10 & 5 & 0 & 95 & 0,935 \\
\hline & 9 & 4,814 & 0,151 & 90,778 & 0,935 \\
\hline & 8 & 4,627 & 0,303 & 86,557 & 0,999 \\
\hline & 7 & 4,441 & 0,545 & 82,335 & 1,031 \\
\hline & 6 & 4,254 & 0,606 & 78,114 & 1,062 \\
\hline & 5 & 4,068 & 0,757 & 73,892 & 1,094 \\
\hline & 4 & 3,881 & 0,909 & 69,671 & 1,126 \\
\hline & 3 & 3,695 & 1,060 & 65,449 & 1,158 \\
\hline & 2 & 3,345 & 4,646 & 64,076 & 1,521 \\
\hline & 1 & 2,996 & 8,231 & 62,702 & 1,883 \\
\hline & 0 & 2,646 & 11,816 & 61,329 & 2,246 \\
\hline \multicolumn{2}{|c|}{ Score } & 1,192 & 9,465 & 6,821 & 0,905 \\
\hline \multicolumn{2}{|c|}{ Weight } & 0,639 & 0,2 & 0,161 & 1 \\
\hline \multicolumn{2}{|c|}{ Value } & 0,761 & 1,893 & 1,098 & 0,905 \\
\hline
\end{tabular}

Gambar 4. Scoring System Proses Make Bulan Agustus

\begin{tabular}{|c|c|c|c|c|}
\hline \multicolumn{2}{|c|}{ No. KPI } & DRL 2.1 & DRS 2.1 & DRS 2.2 \\
\hline \multicolumn{2}{|c|}{ Performance } & 84,163 & 100 & 1 \\
\hline \multirow{11}{*}{ בัป } & $\overline{10}$ & 95 & 100 & 3 \\
\hline & 9 & 91,664 & 99,286 & 2,857 \\
\hline & 8 & 88,329 & 98,571 & 2,714 \\
\hline & 7 & 84,993 & 97,857 & 2,571 \\
\hline & 6 & 81,658 & 97,143 & 2,429 \\
\hline & 5 & 78,322 & 96,429 & 2,286 \\
\hline & 4 & 74,986 & 95,714 & 2,143 \\
\hline & 3 & 71,651 & 95 & 2 \\
\hline & 2 & 69,787 & 93,333 & 1,333 \\
\hline & 1 & 67,924 & 91,667 & 0,667 \\
\hline & 0 & 66,061 & 90 & 0 \\
\hline \multicolumn{2}{|c|}{ Score } & 6,751 & 10 & 1,5 \\
\hline \multicolumn{2}{|c|}{ Weight } & 0,509 & 0,491 & 1 \\
\hline \multicolumn{2}{|c|}{ Value } & 3,436 & 4,910 & 1,500 \\
\hline
\end{tabular}

Return

\section{Gambar 5. Scoring System Proses Deliver dan Return Bulan Agustus}

Setelah dilakukan scoring system untuk masing-masing proses inti, selanjutnya dilakukan pengukuran kinerja supply chain secara keseluruhan untuk bulan Agustus 2016. Dari pengukuran kinerja ini didapatkan indeks total untuk bulan Agustus sebesar 3,698. 
berdasarkan Traffic Light System, nilai indeks total ini berada pada kategori merah yang menunjukkan bahwa performansi perusahaan secara keseluruhan benar-benar dibawah target dan memerlukan perbaikan segera. Untuk hasil pengukuran kinerja supply chain secara keseluruhan bulan Juni 2016 dapat dilihat pada Tabel 6.

Dari hasil pengukuran kinerja masingmasing KPI dengan perhitungan OMAX dan Traffic Light System pada bulan Agustus 2016, dapat diketahui bahwa ada 2 KPI yang termasuk kategori hijau, 7 KPI yang termasuk kategori kuning dan 8 KPI yang termasuk kategori merah. KPI dengan kategori hijau menunjukkan bahwa performansi KPI tersebut telah mencapai target yang ditetapkan perusahaan, sehingga harus tetap dipertahankan. KPI dengan kategori kuning dan merah menunjukkan bahwa performansi KPI tersebut belum mencapai target yang ditetapkan oleh perusahaan sehingga harus diberikan tindakan perbaikan. Namun KPI yang perlu segera mendapatkan prioritas perbaikan adalah KPI dengan kategori merah karena nilai pencapaiannya jauh di bawah target.

Beberapa rekomendasi perbaikan yang dapat dilakukan perusahaaan untuk ke-8 KPI dengan kategori merah dapat dilihat pada Tabel 7.

\section{KESIMPULAN}

Kesimpulan yang dapat diambil dari penelitian ini berdasarkan hasil pengolahan dan analisis hasil, yaitu dari hasil pengukuran kinerja supply chain didapatkan 17 KPI yang valid, yaitu 4 KPI proses plan, 3 KPI proses source, 4 KPI proses make, 3 KPI proses deliver, dan 3 KPI proses return. Selain itu, untuk hasil scoring dengan metode OMAX didapatkan bahwa indeks total pengukuran kinerja supply chain paling rendah berada pada bulan Agustus dengan indeks total sebesar 3,698. Berdasarkan traffic light system, indeks total ini berada pada warna merah yang berarti performansi atau kinerja supply chain secara keseluruhan bulan Agustus 2016 benar-benar di bawah target dan memerlukan perbaikan segera. Pada bulan tersebut, terdapat 2 KPI yang termasuk ke dalam kategori hijau, 7 KPI dengan kategori kuning dan 8 KPI dengan kategori merah. Kemudian untuk ke-8 KPI dengan kategori merah tersebut diberikan rekomendasi perbaikan yang diharapkan dapat membantu memperbaiki supply chain perusahaan.

Tabel 6. Pengukuran Kinerja Supply Chain Perusahaan

\begin{tabular}{|c|c|c|c|c|c|c|c|c|c|}
\hline \multicolumn{2}{|c|}{$\begin{array}{l}\text { Bobot Proses } \\
\text { Inti (A) }\end{array}$} & \multicolumn{2}{|c|}{$\begin{array}{l}\text { Bobot Atribut Kinerja } \\
\text { (B) }\end{array}$} & \multicolumn{2}{|c|}{ Metrik KPI } & $\begin{array}{l}\text { Value } \\
\text { KPI }\end{array}$ & $\begin{array}{c}\text { Total } \\
\text { Value KPI } \\
\text { (C) }\end{array}$ & $\begin{array}{c}\text { Value Atribut } \\
\text { Kinerja } \\
(\mathrm{D}=\mathrm{BxC})\end{array}$ & $\begin{array}{l}\text { Value Proses } \\
\text { Inti (E=DxA) }\end{array}$ \\
\hline \multirow{4}{*}{ Plan } & \multirow{4}{*}{0,174} & & & PRL 1.2 & 0,516 & 3,484 & & & \multirow{4}{*}{1,037} \\
\hline & & Reliability & 0,589 & PRL 1.3 & 0,18 & 1,157 & 5,584 & 3,289 & \\
\hline & & & & PRL 2.1 & 0,305 & 0,944 & & & \\
\hline & & Responsiveness & 0,411 & PRS 3.1 & 1 & 6,500 & 6,500 & 2,6715 & \\
\hline \multirow{3}{*}{ Source } & \multirow{3}{*}{0,315} & Roliability & 0786 & SRL 2.1 & 0,786 & 1,769 & 2397 & 1805 & \multirow{3}{*}{0,736} \\
\hline & & Rellabinty & $0, / 86$ & SRL 2.2 & 0,214 & 0,528 & 2,29I & 1,రUЬ & \\
\hline & & Responsiveness & 0,214 & SRS 2.1 & 1 & 2,483 & 2,483 & 0,531 & \\
\hline \multirow{4}{*}{ Make } & \multirow{4}{*}{0,289} & & & MRL 2.1 & 0,639 & 0,761 & & & \multirow{4}{*}{0,718} \\
\hline & & Reliability & 0,555 & MRL 2.2 & 0,2 & 1,893 & 3,753 & 2,083 & \\
\hline & & & & MRL 2.3 & 0,161 & 1,098 & & & \\
\hline & & Responsiveness & 0,445 & MRS 2.2 & 1 & 0,905 & 0,905 & 0,403 & \\
\hline \multirow{3}{*}{ Deliver } & \multirow{3}{*}{0,133} & Reliability & 0659 & DRL 2.1 & 0,509 & 3,436 & 8346 & 5500 & \multirow{3}{*}{0,800} \\
\hline & & Re & 0,659 & DRS 2.1 & 0,491 & 4,910 & 8,346 & 5,500 & \\
\hline & & Responsiveness & 0,341 & DRS 2.2 & 1 & 1,500 & 1,500 & 0,512 & \\
\hline \multirow{4}{*}{ Return } & \multirow{3}{*}{0,089} & Reliability & 0445 & RRL 1.1 & 0,617 & 1,177 & 2164 & 0963 & \multirow{3}{*}{0,407} \\
\hline & & Rellability & 0,445 & RRL 1.3 & 0,329 & 0,987 & 2,164 & 0,963 & \\
\hline & & Responsiveness & 0,555 & RRS 1.1 & 1 & 6,500 & 6,500 & 3,608 & \\
\hline & \multicolumn{8}{|c|}{ Indeks Total } & 3,698 \\
\hline
\end{tabular}


Tabel 7. Usulan Perbaikan

\begin{tabular}{|c|c|c|c|}
\hline No. KPI & KPI & Usulan Perbaikan & PIC \\
\hline \multirow[b]{2}{*}{ SRL 2.1} & \multirow{2}{*}{$\begin{array}{l}\text { Presentase jumlah } \\
\text { pengiriman bahan baku kayu } \\
\text { yang dapat dipenuhi oleh } \\
\text { supplier }\end{array}$} & $\begin{array}{l}\text { Membuat perjanjian pengiriman bahan baku dengan } \\
\text { kuantitas yang telah ditetapkan setiap bulannya }\end{array}$ & \multirow{2}{*}{$\begin{array}{l}\text { Bagian } \\
\text { Purchasing dan } \\
\text { PPIC }\end{array}$} \\
\hline & & $\begin{array}{l}\text { Menambah jumlah supplier kayu yang sesuai } \\
\text { dengan standar dan kebutuhan perusahaan }\end{array}$ & \\
\hline SRL 2.2 & $\begin{array}{l}\text { Presentase jumlah bahan } \\
\text { baku kayu yang cacat dari } \\
\text { supplier }\end{array}$ & $\begin{array}{l}\text { Melakukan pengecekan langsung ke tempat supplier } \\
\text { bahan baku agar lebih terjamin kualitas dan } \\
\text { kuantitasnya }\end{array}$ & $\begin{array}{l}\text { Bagian } \\
\text { Purchasing dan } \\
\text { PPIC }\end{array}$ \\
\hline SRS 2.1 & $\begin{array}{l}\text { Rata-rata lead time bahan } \\
\text { baku kayu dari waktu pesan } \\
\text { hingga sampai }\end{array}$ & $\begin{array}{l}\text { Membuat perjanjian kontrak hitam di atas putih } \\
\text { yang berisi penalti dan peraturan dalam hal } \\
\text { keterlambatan pesanan bahan baku }\end{array}$ & $\begin{array}{l}\text { Bagian } \\
\text { Purchasing dan } \\
\text { PPIC } \\
\end{array}$ \\
\hline \multirow[b]{2}{*}{ MRL 2.1} & \multirow{2}{*}{$\begin{array}{l}\text { Kehandalan karyawan bagian } \\
\text { produksi dilihat dari } \\
\text { kesesuaian jumlah produk } \\
\text { yang dapat dihasilkan dengan } \\
\text { jumlah karyawan produksi }\end{array}$} & Membuat sistem Reward and Punishment & General Manager \\
\hline & & $\begin{array}{l}\text { Memberikan pelatihan keterampilan kepada } \\
\text { karyawan bagian produksi agar dapat lebih cekatan } \\
\text { dalam mengerjakan pesanan konsumen sehingga } \\
\text { pesanan konsumen dapat diselesaikan tepat waktu }\end{array}$ & Bagian Produksi \\
\hline MRS 2.2 & $\begin{array}{l}\text { Rata-rata waktu pembuatan } 1 \\
\text { produk }\end{array}$ & $\begin{array}{l}\text { Menekankan ketetapan waktu pembuatan } 1 \text { produk } \\
\text { kepada seluruh karyawan bagian produksi agar } \\
\text { dapat mencapai target yang diinginkan }\end{array}$ & Bagian Produksi \\
\hline DRS 2.2 & $\begin{array}{l}\text { Kualitas hubungan dengan } \\
\text { konsumen dilihat dari } \\
\text { kunjungan dari dan ke }\end{array}$ & $\begin{array}{l}\text { Mengadakan gathering bagi para konsumen agar } \\
\text { dapat berkumpul bersama dan berbagi cerita baik } \\
\text { mengenai keluhan produk atau usulan-usulan yang } \\
\text { membangun perusahaan }\end{array}$ & Marketing \\
\hline \multirow{2}{*}{ RRL 1.1} & \multirow{2}{*}{$\begin{array}{l}\text { Persentase produk cacat yang } \\
\text { harus digantikan kepada } \\
\text { konsumen }\end{array}$} & $\begin{array}{l}\text { Meningkatkan standar pengecekan kualitas untuk } \\
\text { produk jadi sebelum di lakukan pengiriman }\end{array}$ & Bagian Produksi \\
\hline & & $\begin{array}{l}\text { ngkajian atau evaluasi dalam } \\
\text { pengiriman }\end{array}$ & $\begin{array}{c}\text { Bagian } \\
\text { Pengiriman }\end{array}$ \\
\hline RRL 1.3 & $\begin{array}{l}\text { Jumlah keluhan mengenai } \\
\text { produk dari konsumen }\end{array}$ & $\begin{array}{l}\text { Membuat lembar keluhan yang berisikan tanggal, } \\
\text { nama konsumen dan jenis keluhan }\end{array}$ & Bagian \\
\hline
\end{tabular}

\section{DAFTAR PUSTAKA}

[1] I Nyoman Pujawan, 2005, Supply Chain Management, Guna Widya, 2005.

[2] Nurus Shubuhi Maulidiya, Nasir Widha Setyanto, Rahmi Yunarti, 2014, Pengukuran Kinerja Supply Chain Berdasarkan Proses Inti Pada Supply Chain Operation Reference (SCOR) (Studi Kasus Pada PT. Arthawenasakti Gemilang Malang), Jurnal Rekayasa dan Manajemen Industri, Vol. 2, No. 4. hal 696-705.

[3] Supply Chain Council, 2010, Supply Chain Operations Reference Version 10.0, SCC, page 7.
[4] Bozoki, Sandor, Janos Fulop., and Lajos Ronyai, 2010, On Optimal Completion of Incomplete Pairwise Comparison Matrices, Vol 52. Juli, 318-333.

[5] Supriyadi, 2013, Analisis Kinerja Rantai Pasok Dengan Metode Analytical Hierarchy Process Studi Kasus PT. Semen Gresik (Persero) Tbk, Universitas Muhammadiyah Gresik. 